\title{
Practicability of passenger vehicle driving emission tests according to new European Union procedures
}

\author{
Jacek Pielecha ${ }^{1,{ }^{*}}$, Remigiusz Jasiński ${ }^{1}$, and Agnieszka Magdziak ${ }^{1}$ \\ ${ }^{1}$ Poznan University of Technology, Faculty of Machines and Transport, ul. Piotrowo 3, 60-965 Poznan, Poland
}

\begin{abstract}
The article compares driving test data using the latest legislative proposals applicable to passenger cars. Several measurements were performed on the same test route in accordance with the RDE test guidelines, which requires a number of criteria to be met. These criteria include: the length of the measuring segments, their overall test time share, and the dynamic characteristics of the drive. A mobile device for reading the EOBD System information was used to record the engine and vehicle operating parameters during tests. This allowed for the monitoring of parameters such as: load value, engine speed and vehicle velocity. The obtained results were then analyzed for their compatibility with the RDE procedure requirements. Despite the same research route, the obtained results were not the same. The analysis also uses the two-dimensional operating time share characteristics expressed in vehicle velocity and acceleration co-ordinates. As a result it was possible to compare the dynamic properties, share of operating time and, consequently, to check the validity of conducted drive tests in terms of their practicability and emission values.
\end{abstract}

\section{Road driving emission tests requirements}

The need to reduce negative impact on the environment has become a key driving force for the sustainable industry development. This has led legislators to adopt more stringent pollutant emission standards for the automotive sector [1-3]. The push towards this practice is still growing, as road transport is considered one of the major sources of pollution in the European Union. Currently, efforts are being made to introduce such emission testing procedures, which would extend to include the operating range of the engine used in real driving conditions $[4,5]$. This is in contradiction to the previous testing procedures, where the exhaust emission values are measured in laboratory conditions (on chassis dynamometer for passenger cars) in the adopted type approval test [6-9]. Moreover, due to the global scope of production and sales of motor vehicles, there is a developing trend of type approval testing procedures unification $[10,11]$.

In January of 2011, the Commission had set up a working group composed of all stakeholders involved to develop a test procedure for real-time emissions that would better reflect the amount of pollutant emission measured in driving tests. To this end, following detailed technical discussions, the variant described in the Regulation (EC) No. 715/2007 [12] was adopted, i.e. the use of portable emission measurement systems (PEMS) and distance emission limit values. As agreed with the stakeholders in the CARS 2020 process, the RDE test procedures should be implemented in two stages: during the first transitional period, test procedures should only be used for emission monitoring purposes and then followed with binding quantitative $\mathrm{RDE}$ requirements for all new type approvals and new vehicles. RDE testing procedures have been introduced in the Commission Regulation (EU) 2016/427 [13]. Currently, quantitative RDE requirements have been established to limit emissions from exhaust systems under all operating conditions in accordance with the distance emission limits set out in Regulation (EC) No. 715/2007.

In order to allow manufacturers to gradually adapt to the RDE testing, the final quantitative RDE requirements should be introduced in two successive stages [13, 14]. In the first stage, which should come into force after 4 years from the mandatory application of the Euro 6 standard, a conformity factor of 2.1 should be used. The second stage should begin 1 year and 4 months after the first stage and should require full compliance with the NOx distance emission limit value of $80 \mathrm{mg} / \mathrm{km}$ as specified in Regulation (EC) No 715/2007 [10], plus a margin, taking into account additional measurement uncertainties resulting from the use of portable emission measurement systems (PEMS) (Table 1).

Table 1. RDE testing requirements in Europe [12, 15].

\begin{tabular}{|c|c|c|c|c|c|c|c|}
\hline 2015 & 2016 & 2017 & 2018 & 2019 & 2020 & 2021 & 2022 \\
\hline \multicolumn{2}{|c|}{ Euro $6 b$} & & \multicolumn{3}{|c|}{ Euro $6 \mathrm{c}$} & \multicolumn{2}{|c|}{ Euro $6 \mathrm{~d}$} \\
\hline \multicolumn{2}{|c|}{ NEDC } & & \multicolumn{5}{|c|}{ WLTC } \\
\hline \multirow{2}{*}{\multicolumn{2}{|c|}{$\begin{array}{l}\text { Research and } \\
\text { concept phase }\end{array}$}} & & \multicolumn{5}{|c|}{ Conformity Factor (CF) } \\
\hline & & & \multicolumn{3}{|c|}{$\begin{array}{l}\mathrm{CF}_{\mathrm{NOx}}=2.1 \\
\mathrm{CF}_{\mathrm{PN}}=1.5\end{array}$} & \multicolumn{2}{|c|}{$\begin{array}{c}\mathrm{CF}_{\mathrm{NOx}}=1.5 \\
\mathrm{CF}_{\mathrm{PN}}=1.5\end{array}$} \\
\hline
\end{tabular}

Corresponding author: jacek.pielecha@put.poznan.pl 
RDEs should cover all possible road situations, using a specific driving styles for the tested vehicles to intentionally alter the results to be more positive or negative that does not result from the technical characteristics of the vehicle, but from a very unusual driving style should be carefully avoided [16-18]. Therefore, complementary boundary conditions for RDE tests (Table 2) are introduced to prevent such situations. Owing to their nature, driving conditions occurring during individual PEMS drive tests cannot fully correspond to the "normal conditions of vehicle operation". The emission control intensity during such tests may therefore vary.

Table 2. Specific requirements for RDE tests $[13,14]$.

\begin{tabular}{|c|c|}
\hline Parameter & Requirement \\
\hline $\begin{array}{l}\text { Ambient } \\
\text { temperature }\left(\mathrm{t}_{\mathrm{a}}\right)\end{array}$ & $\begin{array}{l}\text { - normal range: } 0{ }^{\circ} \mathrm{C} \leq \mathrm{t}_{\mathrm{a}} \leq 30^{\circ} \mathrm{C} \\
\text { - lower extended range: }-7{ }^{\circ} \mathrm{C} \leq \mathrm{t}_{\mathrm{a}}<0{ }^{\circ} \mathrm{C} \\
\text { - upper extended range: } 30^{\circ} \mathrm{C}<\mathrm{t}_{\mathrm{a}} \leq 35^{\circ} \mathrm{C}\end{array}$ \\
\hline $\begin{array}{l}\text { Driving test } \\
\text { altitude }(\mathrm{h})\end{array}$ & $\begin{array}{l}\text { - normal range: } \mathrm{h} \leq 700 \mathrm{~m} \text { a.s.1. } \\
\text { - extended range: } 700 \mathrm{~m} \text { a.s.l. }<\mathrm{h} \leq 1300 \mathrm{~m} \\
\text { a.s.l. }\end{array}$ \\
\hline $\begin{array}{l}\text { Impact } \\
\text { evaluation of } \\
\text { ambient } \\
\text { weather and } \\
\text { road conditions } \\
\text { as well as the } \\
\text { driving style }\end{array}$ & $\begin{array}{l}\text { - total altitude increase: } \\
\text { less than } 1200 \mathrm{~m} / 100 \mathrm{~km} \\
\text { - relative positive acceleration (RPA): } \\
\text { move than } \mathrm{PRA}_{\min } \text { (for all road conditions) } \\
\text { - the product of velocity and acceleration } \\
\left(\mathrm{V} \cdot \mathrm{a}_{\text {pos }}\right) \text { : less than } \mathrm{V} \cdot \mathrm{a}_{\text {pos max }} \text { (for all road } \\
\text { conditions) }\end{array}$ \\
\hline $\begin{array}{l}\text { Vehicle } \\
\text { technical state } \\
\text { before the test }\end{array}$ & $\begin{array}{l}\text { - engine cold start: cooling liquid temperature } \\
\text { below } 70^{\circ} \mathrm{C} \text {, time at least } 300 \mathrm{~s} \\
\text { - cold start emission results not counted } \\
\text { towards the RDE test results }\end{array}$ \\
\hline $\begin{array}{l}\text { Any vehicle } \\
\text { stop }\end{array}$ & - no longer than $180 \mathrm{~s}$ \\
\hline $\begin{array}{l}\text { Vehicle } \\
\text { aftertreatment } \\
\text { systems } \\
\text { operation }\end{array}$ & $\begin{array}{l}\text { - a single regeneration of the particulate filter } \\
\text { justifies repeating the RDE test; the } \\
\text { occurrence of two filter regenerations is to be } \\
\text { included in the results of the RDE test }\end{array}$ \\
\hline $\begin{array}{l}\text { Driving comfort } \\
\text { systems } \\
\text { operation }\end{array}$ & $\begin{array}{l}\text { - regular use as intended by the manufacturer } \\
\text { (for example: use of the air conditioning) }\end{array}$ \\
\hline Vehicle load & $\begin{array}{l}\text { - vehicle mass: driver (and passenger) along } \\
\text { with the PEMS equipment; maximum load < } \\
90 \% \text { of the sum of the mass of the } \\
\text { passengers and the vehicle curb weight }\end{array}$ \\
\hline $\begin{array}{l}\text { Test } \\
\text { requirements }\end{array}$ & - duration $90 \mathrm{~min}-120 \mathrm{~min}$ \\
\hline $\begin{array}{l}\text { Urban test } \\
\text { portion } \\
\text { requirements }\end{array}$ & $\begin{array}{l}\text { - } 29 \%-44 \% \text { share of the whole test time } \\
\text { - distance: more than } 16 \mathrm{~km} \\
\text { - vehicle velocity: up to } 60 \mathrm{~km} / \mathrm{h} \\
\text { - average velocity: } 15 \mathrm{~km} / \mathrm{h}-40 \mathrm{~km} / \mathrm{h} \\
\text { - vehicle stop: } 6 \%-30 \% \text { of the urban portion } \\
\text { of the test time }\end{array}$ \\
\hline $\begin{array}{l}\text { Rural test } \\
\text { portion } \\
\text { requirements }\end{array}$ & $\begin{array}{l}\text { - } 23 \%-43 \% \text { share of the whole test time } \\
\text { - distance: more than } 16 \mathrm{~km} \\
\text { - vehicle velocity (V): } 60 \mathrm{~km} / \mathrm{h}<\mathrm{V} \leq 90 \mathrm{~km} / \mathrm{h}\end{array}$ \\
\hline $\begin{array}{l}\text { Motorway test } \\
\text { portion } \\
\text { requirements }\end{array}$ & $\begin{array}{l}\text { - } 23 \%-43 \% \text { share of the whole test time } \\
\text { - distance: more than } 16 \mathrm{~km} \\
\text { - vehicle velocity: more than } 90 \mathrm{~km} / \mathrm{h} \\
\text { - vehicle velocity over } 100 \mathrm{~km} / \mathrm{h} \text { for at least } 5 \mathrm{~min} \\
\text { - vehicle velocity over } 145 \mathrm{~km} / \mathrm{h} \text { no more than } \\
3 \% \text { of the test portion time }\end{array}$ \\
\hline
\end{tabular}

Therefore, and in order to account for the uncertainty of statistical and technical measurement procedures, in the future it may be possible to reflect in the distance emission limits, applicable to individual PEMS test drives, the characteristics of these drives, as determined by measurable parameters such as driving dynamics or engine load [19]. But in this case, it should not lead to an increased environmental impact and lowered effectiveness of RDE testing procedures, which should be demonstrated through peer-reviewed research tests. In addition, when assessing the emission control intensity in PEMS testing, only parameters that may be justified by objective scientific considerations, not just engine calibration, pollution control or emission control systems, should be considered [20].

\section{Research methodology}

\subsection{Data collection}

The Mobile EOBD Read System - TEXA OBD Log [21] (Fig. 1) was used for the test. This allowed the recording of engine parameters at $1 \mathrm{~Hz}$ directly after connecting it to the diagnostic socket. Values such as: sampling time, engine speed and load were monitored. In addition to the data from the motor controller, a GPS location signal was recorded. It is worth noting that during the tests the parameters recorded from the EOBD system [20] were stored in the memory of the TEXA OBD Log reader without the possibility of their continuous visualization.

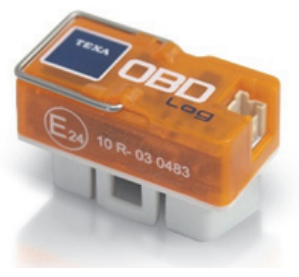

Fig. 1. TEXA OBD Log mobile read system [21].

\subsection{Exhaust emission measurement}

The testing apparatus is presented in Fig. 2a. A portable Semtech DS analyzer [23] was used for the measurement of the exhaust emission from vehicles (Fig. 2b). It allowed measurements of carbon monoxide, carbon dioxide, hydrocarbons, non-methane hydrocarbons and nitrogen oxides exhaust emission.

A portable AVL MOVE PM (Micro Soot Sensor + gravimetric particulate measurement) analyzer was used to measure particle mass (Fig. 3a), while a PMPcompliant AVL condensation particle counter [24] was used to measure particle number (Fig. 3b; it is important to note that in accordance with the legislation, this device only measures solid particle). In terms of benchmarking and quality control, zero-span checks were performed before and after each measurement. A linearization of the equipment was carried out every three months. Post-processing plausibility checks were 
made on all data, focusing on $\mathrm{CO}_{2}$, to ensure that the data collected was realistic; results from the Micro Soot Sensor were compared with PM and PN results to check their plausibility. The emission measurement equipment had a maximum mass of $116 \mathrm{~kg}$ (Gas PEMS - $25 \mathrm{~kg}$; PM PEMS - $45 \mathrm{~kg}$, PN Counter - $25 \mathrm{~kg}$ ), together with an additional power supply (generator) $-21 \mathrm{~kg}$. The total flow rate of the combined sample streams was approx. $20 \mathrm{dm}^{3} / \mathrm{min}$. This was judged not to have any impact on the operation of the test vehicles or their engines, even when idle.

a)

b)

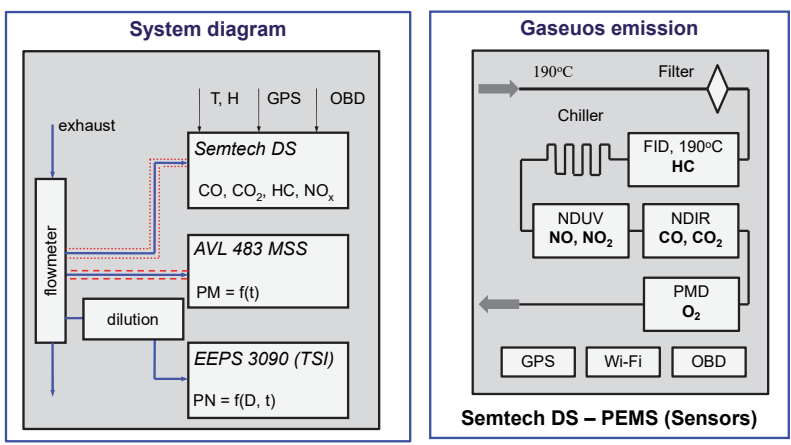

Fig. 2. The measuring systems used for testing under real driving conditions.

a)

b)

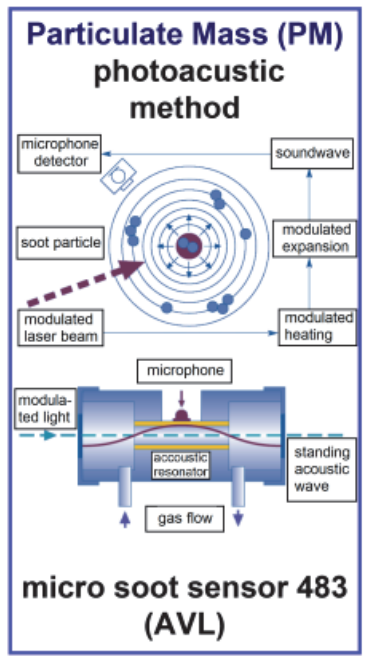

Fig. 3. Measurement system used for testing particle emission: a) analyser for measurement of the particle mass concentration - AVL MOVE (micro soot sensor + gravimetric), b) particle counter (AVL) for measurement of particle number.

\subsection{Test route characteristics}

Measurements were made 8 times conforming to the real driving conditions in urban, non-urban and motorways in Poznan and its surroundings. The average distance traveled was $80.2 \mathrm{~km}$. Figure 4 shows an example of a route. The test route has been chosen so that it meets the requirements of the European Commission as described in the Regulation [13, 14], with particular attention paid to its topography. Table 3 shows the characteristics of the route in terms of terrain.

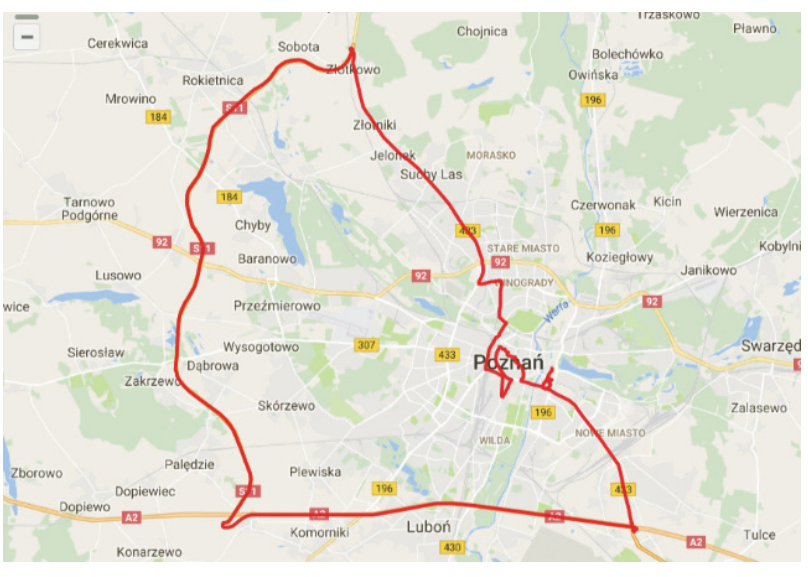

Fig. 4. Test route example.

Table 3. Topography characteristics of the test route.

\begin{tabular}{|c|c|}
\hline Parameter & Test route \\
\hline Altitude: & 52 \\
minimum [m] & 82 \\
average [m] & 109 \\
maximum [m] & \\
Maximum slope: & 4.1 \\
increase [\%] & -3.7 \\
decrease [\%] & \\
\hline
\end{tabular}

The topography analysis of the test route confirms its compliance with the test requirement of the altitude difference between the start and end points of the test to not exceed $100 \mathrm{~m}$. In addition, it was possible to distinguish between urban, non-urban and motorway sections.

\section{Vehicle parameter analysis}

In spite of traveling on a similar route, the results obtained varied. In Figure 5 results from all test drives are shown using the $V=\mathrm{f}(S)$ relationship. It shows the division of the research route into 3 portions: urban $(0 \mathrm{~km} / \mathrm{h}-60 \mathrm{~km} / \mathrm{h})$, rural $(60 \mathrm{~km} / \mathrm{h}-90 \mathrm{~km} / \mathrm{h})$ and motorway $(90 \mathrm{~km} / \mathrm{h})$. In spite of the similar research route, both the velocity results as well as its average values in the individual test portions are not the same. The driving parameters defined by acceleration, constant velocity, braking and stopping are similar. These parameters are systematized in Fig. 4a-d. The average values were: for acceleration $-24.6 \%$, constant driving velocity $-34.7 \%$, braking $-23.6 \%$, and for parking $16.9 \%$.

Detailed requirements of the RDE road test standard are given below, where the verification of individual driving parameters (defined earlier) conformity has been demonstrated, and their values are compared also giving the permitted ranges (if required) and with mean values also determined.

The analysis of test distance data in the urban part showed that drive No. 2 was characterized by the longest distance traveled and the drive No. 4 with the shortest. However, the values of the distance covered for all test drives were within the permissible range, i.e. they were more than $16 \mathrm{~km}$ (Fig. 6a). 


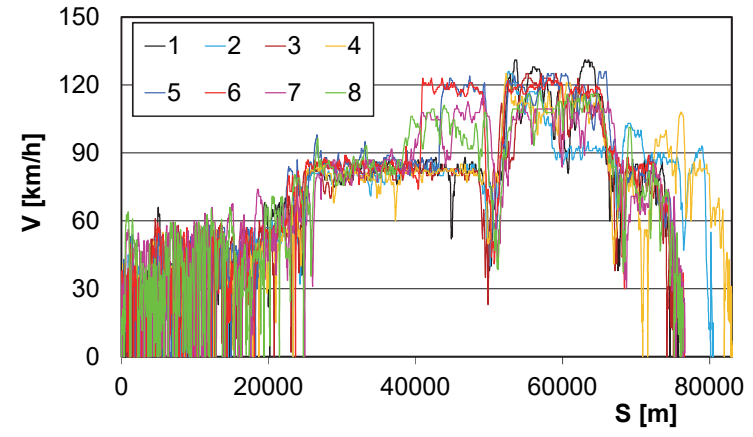

Fig. 5. Vehicle velocity for all RDE test drives.

Table 4. Drive parameters (acceleration, constant vehicle velocity, braking, stops) against the mean value.

\begin{tabular}{|c|c|c|c|c|}
\hline \multirow{2}{*}{$\begin{array}{c}\text { Test drive } \\
\text { number }\end{array}$} & \multicolumn{4}{|c|}{ Share [\%] } \\
\cline { 2 - 5 } & $a>0$ & $V=$ const & $a<0$ & $V=0$ \\
\hline Drive 1 & 20 & 39 & 20 & 21 \\
\hline Drive 2 & 20 & 51 & 19 & 10 \\
\hline Drive 3 & 22 & 41 & 20 & 17 \\
\hline Drive 4 & 21 & 41 & 20 & 18 \\
\hline Drive 5 & 23 & 34 & 23 & 19 \\
\hline Drive 6 & 26 & 34 & 26 & 14 \\
\hline Drive 7 & 33 & 21 & 30 & 16 \\
\hline Drive 8 & 32 & 17 & 31 & 20 \\
\hline Average & 24.6 & 34.7 & 23.6 & 16.9 \\
\hline
\end{tabular}

a)

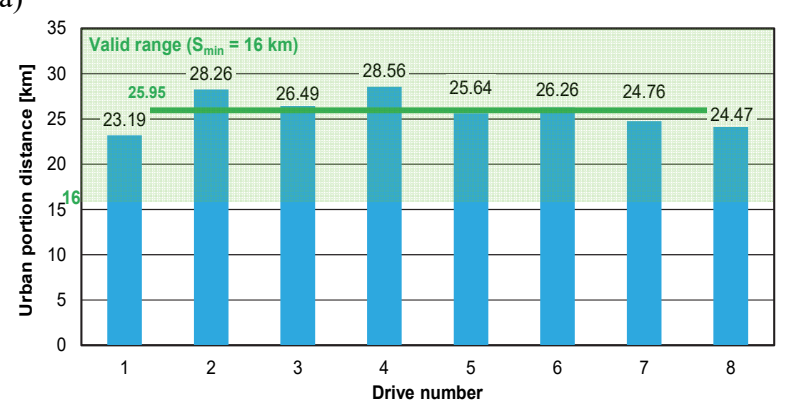

b)

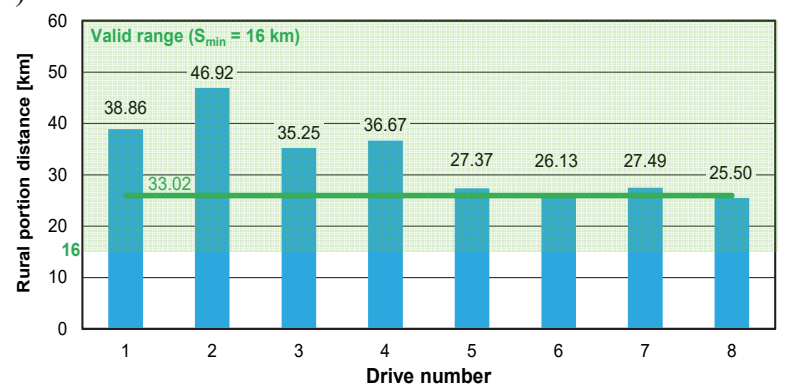

c)

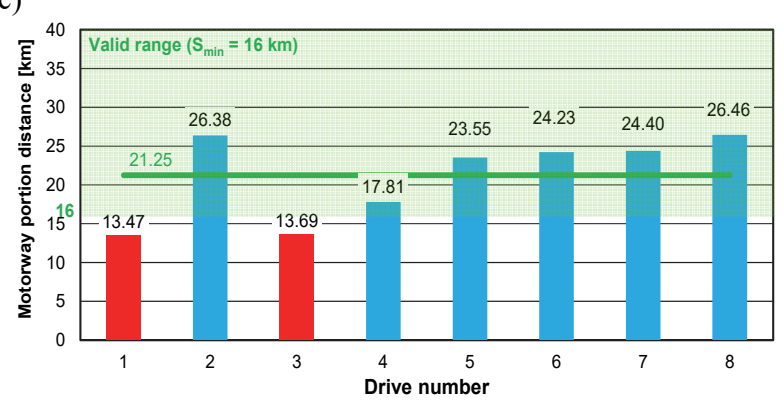

Fig. 6. Travel distance comparison of urban (a), rural (b) and motorway (c) test drives with the minimum distance (required) for all drives and the mean value.
Analysis of the travelled distance data in the rural portion showed that drive No. 2 was characterized by the longest distance traveled and the drive No. 8 with the shortest distance. The values of the distance covered for all test drives were within the permissible range, i.e. they were more than $16 \mathrm{~km}$ (Fig. 6b). The distance travelled on the motorway was the longest for the drive No. 8 and the shortest for the drive 1 . The distance of the drives No. 1 and No. 3 were too small. Other drives were within the acceptable range, i.e. their distance was longer than $16 \mathrm{~km}$ and mean was $21.25 \mathrm{~km}$ (Fig. 6c).

The percentage time share of the urban portion in the drive tests was the largest for drive No. 3, and the smallest for drive No. 2. The percentages of urban share of all drives (except for drive No. 2) were within the permissible range of $29 \%-44 \%$ (Fig. 7a). The percentage time share of the non-urban portion in the drive tests was the largest for the drive No. 1, and the lowest for the drive No. 8. Only the values obtained from the drives No. 5-8 were within the acceptable range of $23 \%-43 \%$. Others did not meet this requirement (Fig. $7 \mathrm{~b})$. The analysis of percentage time share data of the motorway section in the drive tests showed that the highest value was for the drive No. 8, and the smallest for the drive No. 1. The shares of the motorway portion were within the permissible range of $23 \%-43 \%$ (Fig. $7 \mathrm{c})$ except for the values of drives No. 1, 3 and 4.

a)

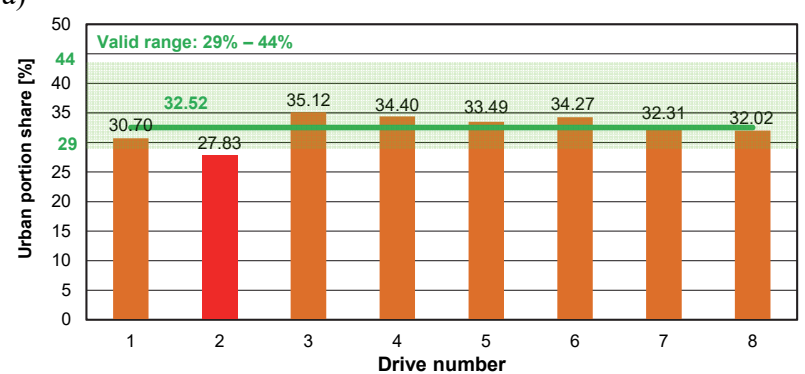

b)

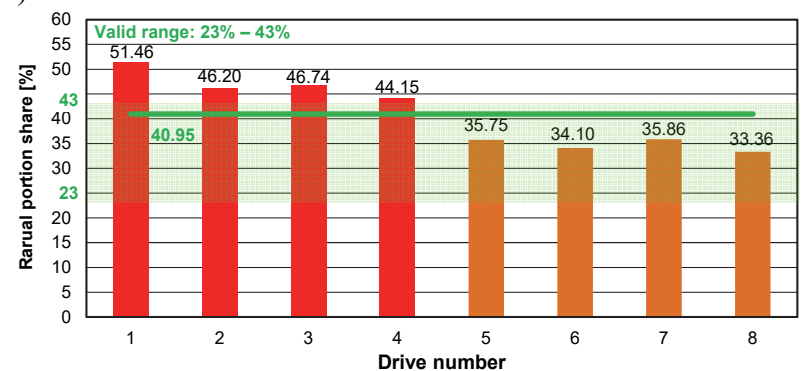

c)

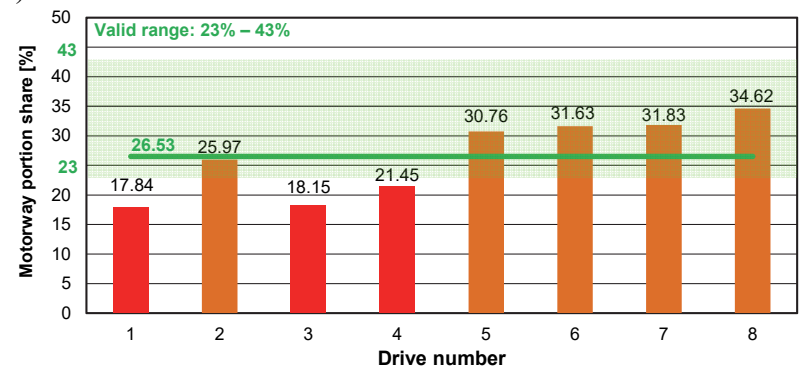

Fig. 7. Test time share comparison of urban (a), rural (b) and motorway (c) test drives with the minimum value (required) for all drives and the mean value. 
Analysis of the average velocity data in urban test portion showed that the highest value was achieved in drive No. 2 and the smallest in drive No. 1. The average speed values of all drives are within the permissible range, i.e. between $15 \mathrm{~km} / \mathrm{h}$ and $40 \mathrm{~km} / \mathrm{h}$ (Fig. 8a).

Analysis of the average velocity data in non-urban test portion showed that the highest value was achieved in drive No. 5, and the smallest in drive No. 7. The average velocity for all drives were similar, although the legislator did not specify the permissible velocity range (Fig. 8b)

Analysis of the average velocity data in the motorway section showed that the highest value was achieved in the drive No. 1 and the lowest in the drive No. 2. The average velocity values did not have the permissible range defined (Fig. 8c).

a)

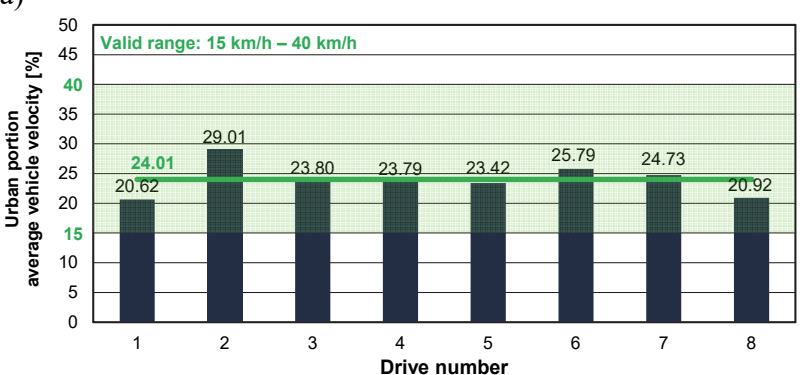

b)

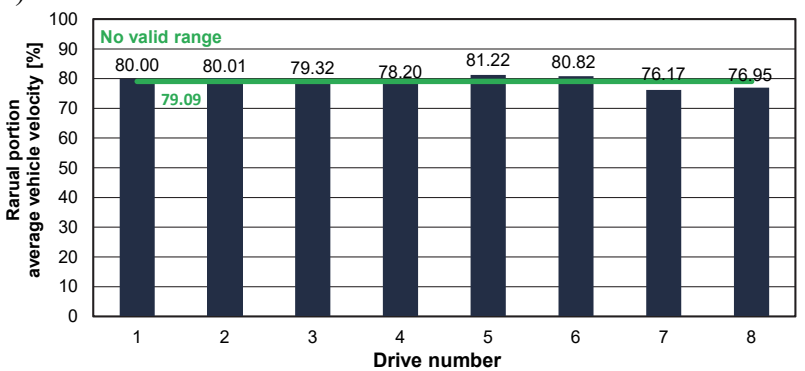

c)

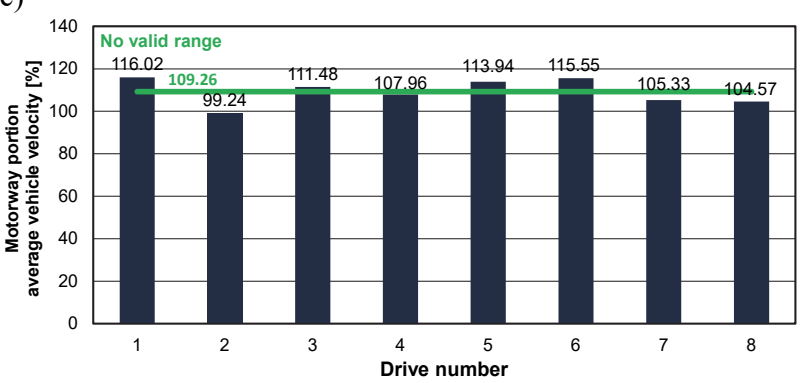

Fig. 8. Average vehicle velocity comparison of urban (a), rural (b) and motorway (c) test drives with the minimum velocity (required) for all drives and the mean value.

The duration of the test was the longest for drive No. 4 and the shortest for drive No. 6. All drives were carried out within an acceptable time range, i.e. 90 minutes to 120 minutes (Fig. 9).

Analysis of the drive test duration data at velocity above $100 \mathrm{~km} / \mathrm{h}$ in the motorway section showed that the highest value was achieved by the drive No. 7 and the smallest in drive No. 2. In all drives the value is higher than the permissible range, i.e. more than 5 minutes (Fig. $10)$.

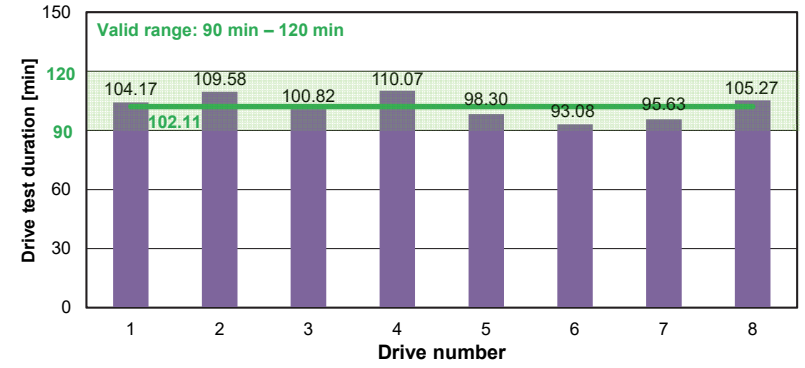

Fig. 9. Comparison of the drive test duration with the limit values (required) for all drives and with mean values shown.

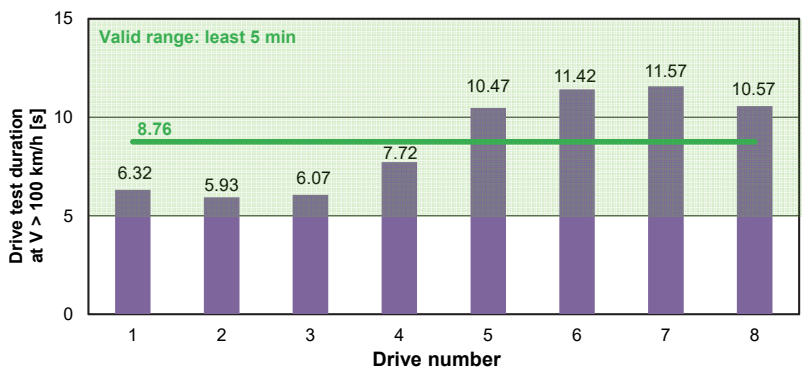

Fig. 10. Comparison of the drive duration with a velocity over $100 \mathrm{~km} / \mathrm{h}$ on the motorway section of the test with the limit value (required) and the mean value shown for all drives.

Analysis of time share data of vehicle being immobile in the urban drive showed that the highest value was noted for drive No. 1 and the smallest for drive No. 2. All drives reached the stop time share within the permissible range, i.e. $6 \%-30 \%$. With the exception of drive No. 1 which was the only one that did not fulfill this requirement (Fig. 11).

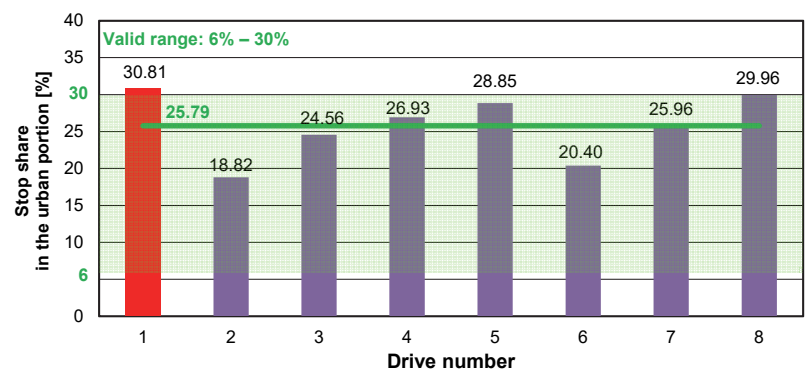

Fig. 11. Share of time spent stationary for the urban portion of the drive test with the limit values (required) for all drives and with mean values shown.

Analysis of the RPA dynamics data in the urban portion showed that the highest value was achieved in drive number No. 8 and smallest for drive No. 2. All drives reached a value greater than the permissible value based on the average velocity in the urban part (Fig. $12 \mathrm{a})$.

The analysis of the RPA dynamics data in the nonurban portion showed that the highest value was obtained in the drive No. 8 and the smallest for drive No. 3. Drives number 1-3 did not exceed the minimum required value, i.e. they were incorrect, as opposed to the other drives (Fig. 12b).

Analysis of the RPA dynamics data in the motorway test portion showed that the highest value was achieved 
in drive No. 1 and smallest in drive No. 6. All the drives reached a value greater than the minimum required value dependent on the average velocity in the motorway section (Fig. 12c).

a)

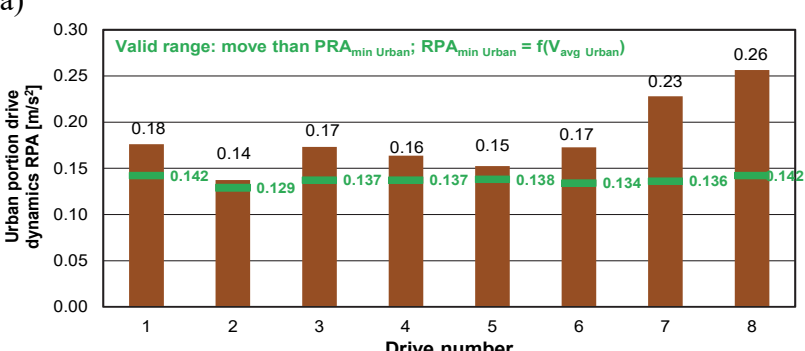

b)

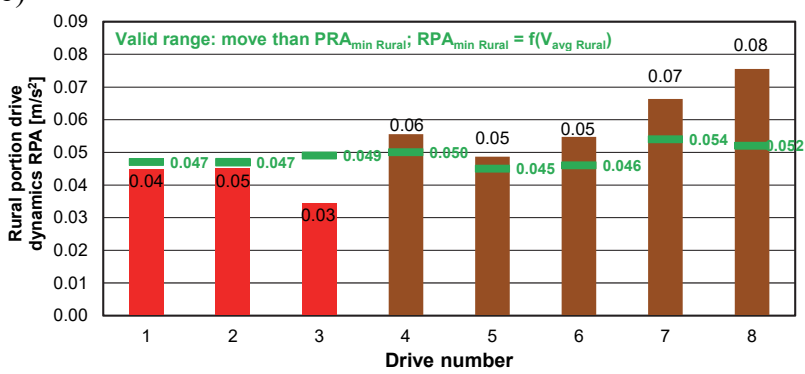

c)

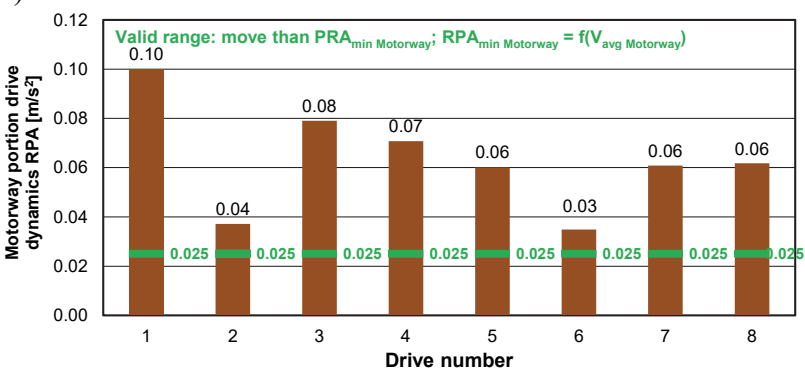

Fig. 12. Relative positive acceleration comparison of urban (a), rural (b) and motorway (c) test drives with the minimum value (required) for all drives and the mean value.

The analysis of the $95^{\text {th }}$ percentile of the product of velocity and acceleration values for the urban portion of the test showed that the value was the highest for the $8^{\text {th }}$ and the smallest for the $2^{\text {nd }}$ drive. The values for all the drives were within the acceptable range, i.e. they were less than the maximum determined based on the average velocity in the urban part (Fig. 13a).

The analysis of the data for the $95^{\text {th }}$ percentile of the product of velocity and acceleration in the non-urban portion of the test showed that the value was the highest for drive No. 6 and the lowest for drive No. 2. The values of all drives were within the acceptable range, based on the average velocity in the non-urban part (Fig. $13 b)$.

The analysis of the data for the $95^{\text {th }}$ percentile of the product of velocity and acceleration in the motorway portion of the test showed that the value was the highest for drive No. 6 and the lowest for drive No. 7. The value of all drives was within the acceptable range, i.e. they did not exceed the maximum value, determined by the average velocity in the motorway section (Fig. 13c).

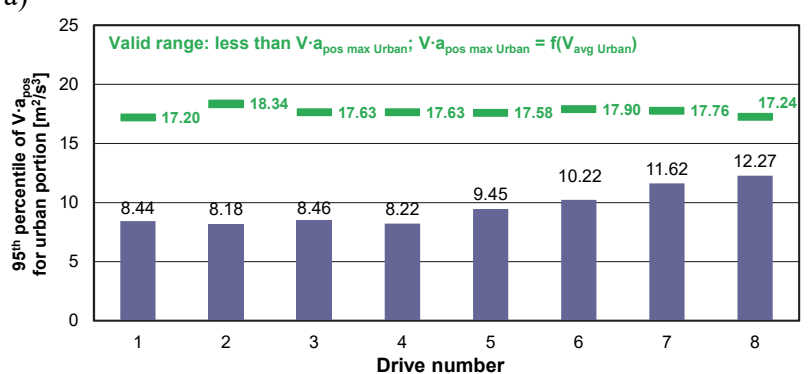

b)

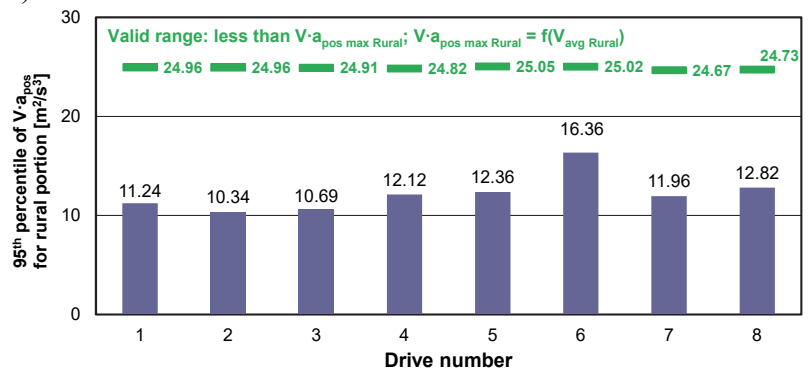

c)

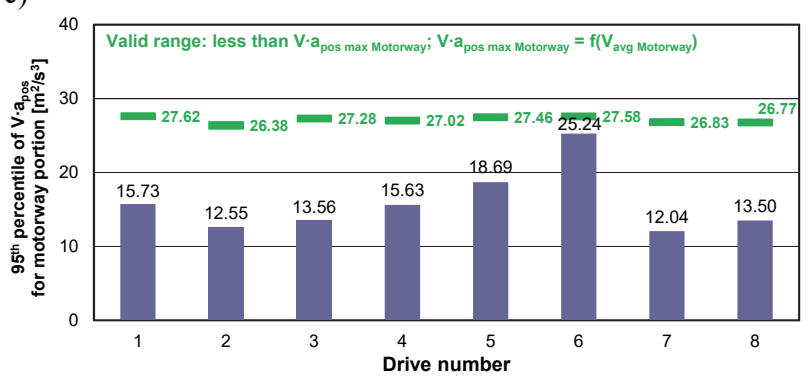

Fig. 13. Vehicle velocity and acceleration product $95^{\text {th }}$ percentile comparison of urban (a), rural (b) and motorway (c) test drives with the maximum value (required) for all drives.

From the data presented in the Figures 6-12 it can be seen that the drives 1-4 only slightly differ from the guidelines for which the test should meet all requirements. In these cases, as non-compliant (the drives that fail to meet the criteria are shown on the graph in red) the following parameters can be listed: too short distance travelled on the motorway (drives No. 1 and 3), urban drive share too small (drive No. 2), too large share of the non-urban drive portion (drives No. 1, 2, 3 and 4), too small share of the motorway drive portion (drives No. 1, 3 and 4), too much time spent stationary in the urban portion (drive No. 1), too low drive dynamics in the non-urban portion (drives No. 1, 2 and 3 ).

Test drives number 5 to 8 meet all the requirements of the RDE procedure. In the remainder of the article the practicability study of the tests was performed based on the presented results for all drives, with only selected ones being presented.

\section{Analysis of the results in the vehicle velocity-acceleration co-ordinates}

The two-dimensional time share characteristics compiled in vehicle velocity-acceleration co-ordinates were used to compare the dynamic properties of the drive tests 
performed. The purpose of this characteristic is to replace the whole test drive with data points and to allow determining of the operating time share within the defined velocity and acceleration intervals. Although this characteristic does not take into account the dynamic properties of the vehicle, the published results of such an

a)

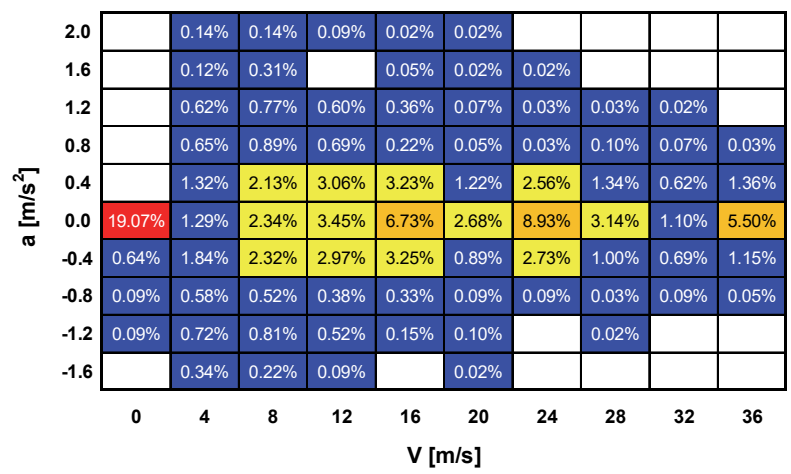

b)

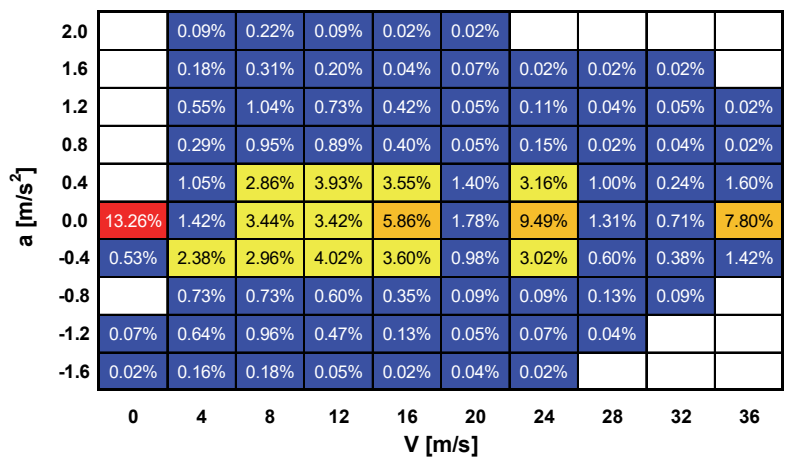

c)

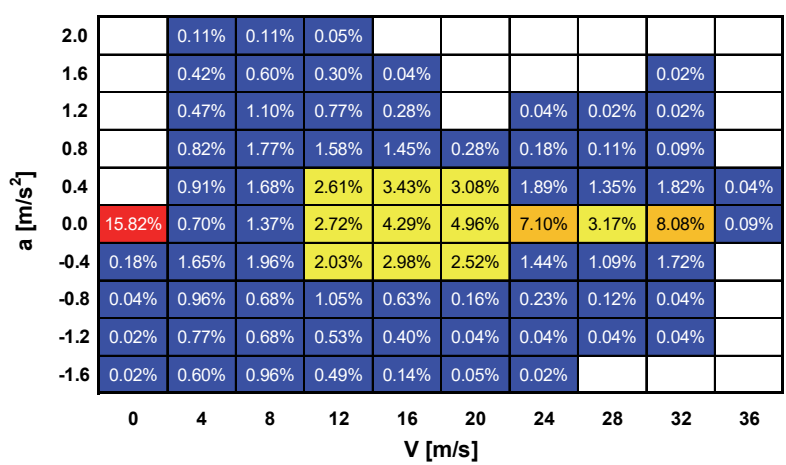

d)

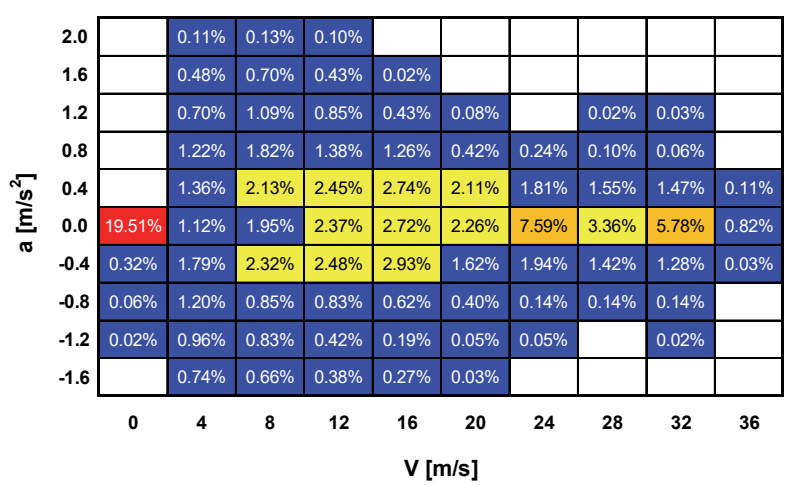

Fig. 14. Share of vehicle operating time in individual velocity and acceleration intervals: a) for drive No. 5, b) for drive No. 6 , c) for drive No. 7, d) for drive No. 8 . optimization using this two-dimensional curve indicate that such a simplification is acceptable.

Figure 14 shows the two-dimensional characteristics of the vehicle's operating time for the drives that meet all the test requirements (drives No. 5-8), which can be characterized as follows: the highest operating time share of the vehicle in real driving test conditions is taken by the vehicle idle mode and the constant mean velocity values $\left(V=16 \mathrm{~m} / \mathrm{s}-36 \mathrm{~m} / \mathrm{s}\right.$ for $\left.a=0 \mathrm{~m} / \mathrm{s}^{2}\right)$.

For all drives, the largest share of vehicle operating time is in idle and the average velocity $(V=24 \mathrm{~m} / \mathrm{s}$ for $a=0 \mathrm{~m} / \mathrm{s}^{2}$ except for drive No. 7). This is due to the constant driving velocity when travelling through in the non-urban area. In the case of drives that meet the test requirements, the extension of the vehicle's operating range into the variable acceleration values in the range of $\left(-0.4 \mathrm{~m} / \mathrm{s}^{2}, 0.4 \mathrm{~m} / \mathrm{s}^{2}\right)$ can be seen. The acceptable drives were the ones numbered 5-8 and the average values for those drives were designated as "benchmark" values (Fig. 15).

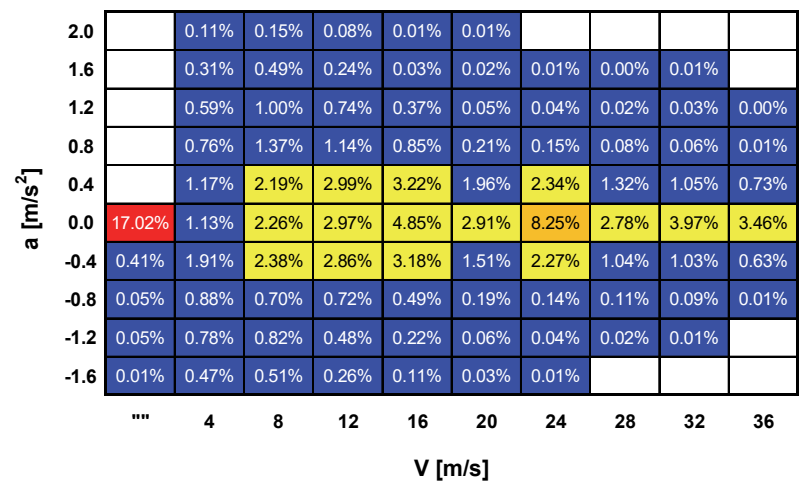

Fig. 15. Share of vehicle operating time in individual speed and acceleration ranges for the "benchmark" values.

\section{Comparison of road emission tests practicability}

The test cross-compliance comparison was performed by comparing the corresponding areas from the "benchmark" two-dimensional curve and the characteristic obtained from the drives No. 5-8 (for the remaining drives only the final values are given in Tab. 5).

Table 5. The values of the straight-line coefficient and the determination coefficient obtained from the comparison of the "benchmark" drives with all the drives No. 1-8.

\begin{tabular}{|c|c|c|c|}
\hline $\begin{array}{c}\text { Drive } \\
\text { No. }\end{array}$ & $\begin{array}{c}\text { Straight-line } \\
\text { coefficient }\end{array}$ & $\begin{array}{c}\text { Determination } \\
\text { coefficient }\end{array}$ & $\begin{array}{c}\text { Number of } \\
\text { disqualifying } \\
\text { parameters }\end{array}$ \\
\hline 1 & 0.752 & 0.852 & 5 \\
\hline 2 & 0.695 & 0.558 & 3 \\
\hline 3 & 0.776 & 0.805 & 4 \\
\hline 4 & 0.800 & 0.868 & 2 \\
\hline 5 & 0.895 & 0.956 & 0 \\
\hline 6 & 0.964 & 0.854 & 0 \\
\hline 7 & 0.960 & 0.890 & 0 \\
\hline 8 & 0.924 & 0.941 & 0 \\
\hline
\end{tabular}


The operating time share in the various vehicle velocity and acceleration ranges was compared resulting in a set of points for which the straight-line coefficient and the determination coefficient were calculated. These values determine the relationship between the researched variables (Fig. 16).

a)

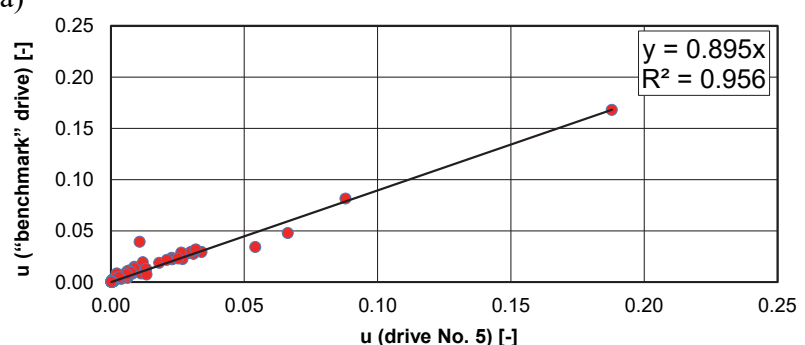

b)

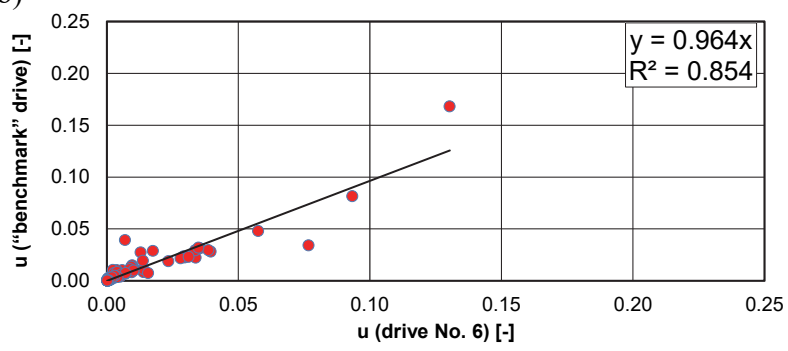

c)

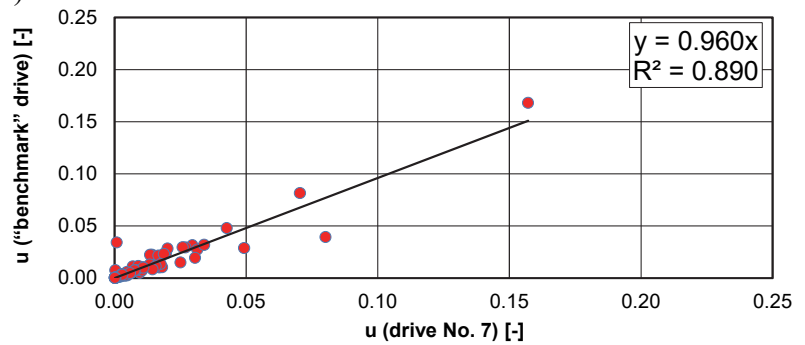

d)

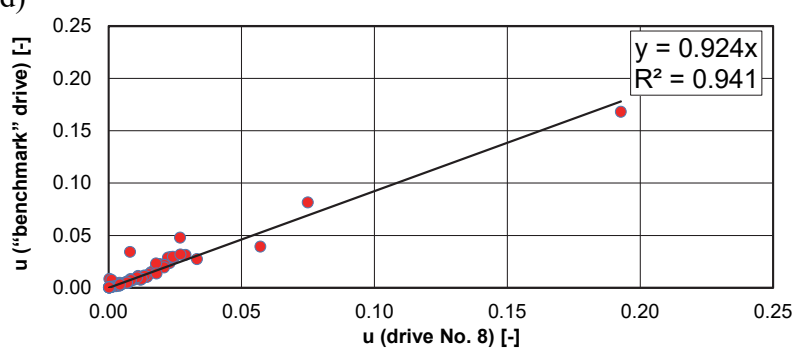

Fig. 16. Comparison of the vehicle operating time share in each velocity and acceleration compartment of the "benchmark" drive and: a) the drives No. 5, b) drive No. 6, c) drive No.7, d) drive No. 8.

Table 5 adds a parameter characterizing the number of disqualifying parameters, ones that to not fall within the permissible ranges (marked in red). The analysis of the data contained in Table 5 indicates that the discarded drives (No. 1-4) are characterized by the smallest straight line coefficient (in the range of 0.695-0.800), while for the acceptable drives the value of this coefficient ranges from 0.895 to 0.964 . It should be noted that the accuracy of the test performed depends mainly on the straight-line coefficient value and much less on the value of the determination coefficient (Fig. 17).

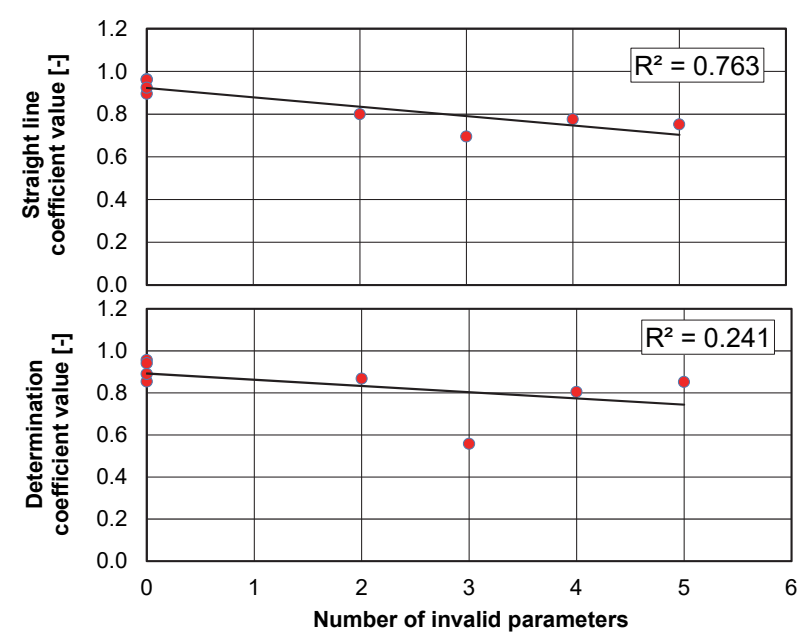

Fig. 17. The relationship between the straight-line coefficient and the determination coefficient from the number of disqualifying parameters.

\section{Exhaust emission results}

Previous studies with simultaneous emission measurement were used to determine the distance emission of pollutants. Due to the fact that the study was carried out for a passenger vehicle equipped with a Euro $6 \mathrm{~b}$ gasoline engine (without a particulate filter - GPF), the emission values of carbon dioxide, carbon monoxide, hydrocarbons, nitrogen oxides and particle number were measured (Fig. 18). The results were presented for all eight test drives, indicating that the first four drives did not meet the formal requirements (marked in red), although this fact was not a disqualifying factor for determining distance emission. The disqualified drives were marked in red, whereas the range of values found in the acceptable drives (for drives No. 5-8) was marked in green.

The distance emission limits shown in Figure 18, labeled Euro 6d-Temp, refer to future emission standards (to be adopted from 1.09.2017), where the distance emission limit values are set as: for nitrogen oxides at 2.1, for particle number at 1.5 relative to the Euro $6 \mathrm{~b}$ distance emission limits.

The analysis of the individual emission values of pollutants indicates the similar character of the obtained test data, which is discussed below.

The maximum value of carbon dioxide distance emission obtained in the test (Fig. 18a) for observed for drive number $8(211.5 \mathrm{~g} / \mathrm{km})$, while the minimum value $(185.1 \mathrm{~g} / \mathrm{km}$ ) for drive number 6 (for the acceptable drives). It should be noted that the drive number 8 is characterized by the greatest driving dynamics (relative positive acceleration, Fig. 12). However, considering all the drives, the minimum value of carbon dioxide emission obtained was $172.2 \mathrm{~g} / \mathrm{km}$, which was obtained for drive No. 2 - although this drive did not meet the RDE test requirements (which requires the lowest driving dynamics).

The maximum value of carbon monoxide distance emission (Fig. 18b) for the accepted drives was 356 $\mathrm{mg} / \mathrm{km}$ (drive No. 8) and the smallest was $264 \mathrm{mg} / \mathrm{km}$ 
a)

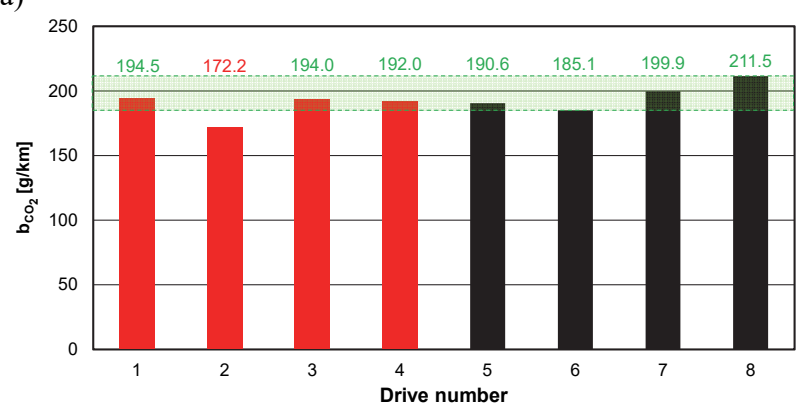

b)

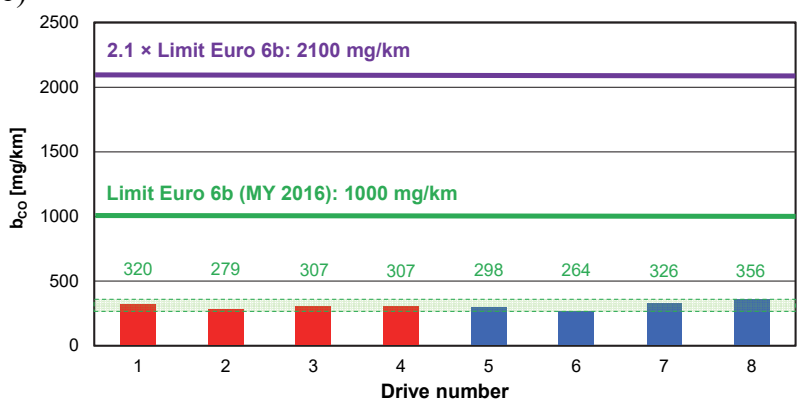

c)

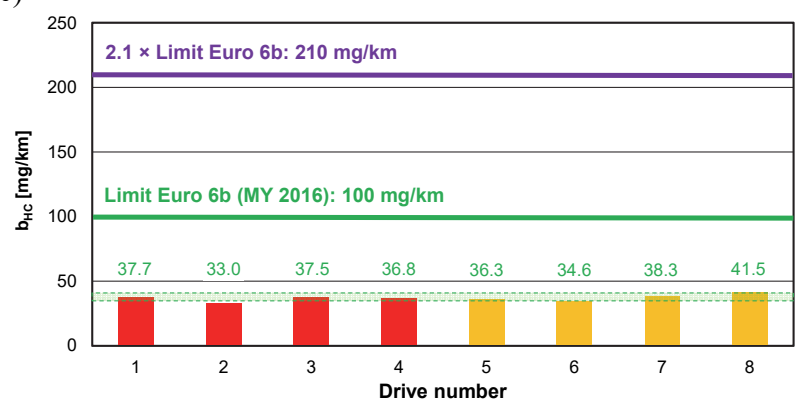

d)

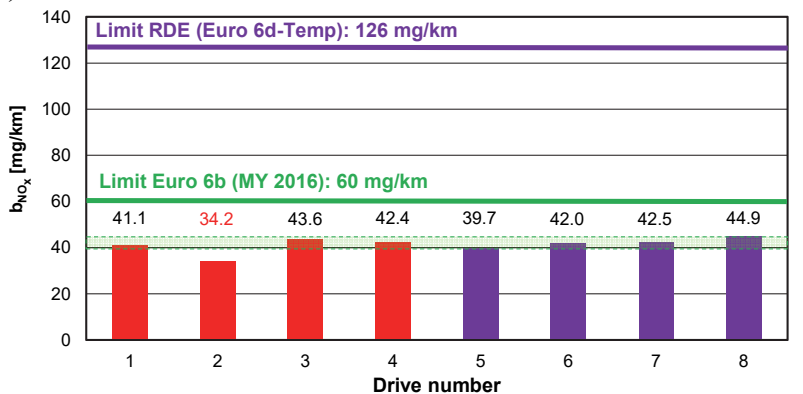

e)

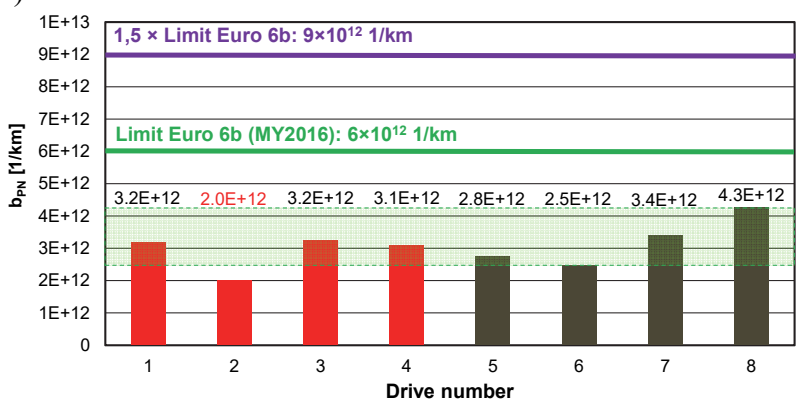

Fig. 18. Distance emission results for: a) carbon dioxide, b) carbon monoxide, c) hydrocarbons, d) nitrogen oxides, and e) particle number for all drives; the disqualified passages are shown in red, while the range of parameter value changes from valid drives (No. 5-8) are shown in green. (drive No. 6). Test drive number 6 was characterized by a small RPA value, even relative to other accepted drives. The distance emission values in all the performed test drives did not exceed the Euro $6 \mathrm{~b}$ limit values for passenger vehicles equipped with petrol engines (1000 $\mathrm{mg} / \mathrm{km})$.

The extreme hydrocarbons distance emission values (Fig. 18c) were obtained for the same drives as the ones for the distance emission of nitrogen oxides. The maximum value is $41.5 \mathrm{mg} / \mathrm{km}$ (drive No. 8) and the minimum is $34.6 \mathrm{mg} / \mathrm{km}$ (drive No. 6). The quoted values did not exceed the Euro $6 \mathrm{~b}$ distance emission limit of $100 \mathrm{mg} / \mathrm{km}$.

The distance emission of nitrogen oxides (Fig. 18d) varied between $39.7 \mathrm{mg} / \mathrm{km}$ (drive No. 5) and 44.9 $\mathrm{mg} / \mathrm{km}$ (drive No. 8) for the acceptable drives. The value of distance emission did not exceed the distance emission limit, i.e. $60 \mathrm{mg} / \mathrm{km}$, for any of the drives.

The nature of the particle number was similar to the previous results (Fig. 18e): the highest value was obtained for drive number $8\left(4.3 \times 10^{12} 1 / \mathrm{km}\right)$, and the lowest for drive number $6\left(2.5 \times 10^{12} 1 / \mathrm{km}\right)$.

In order to compare the distance emission change ranges for the individual exhaust gas components, a relative error of the calculated emission was determined for each component, in each drive, described by the equation:

$$
\Delta b_{j}=\frac{b_{j, \operatorname{avg}(5-8)}-b_{j}}{b_{j}}
$$

where:

$b_{j, \text { avg(5-8) }}$ - average distance emission value from the drives numbered 5-8,

$b_{j} \quad-$ specific distance emission value of the given substance.

An analysis of the individual relative error values allows for the following observations to be made:

- The relative error value for carbon dioxide distance emission (Fig. 19a) indicates that it does not exceed $8 \%$ for the correctly conducted RDE test that meet all the requirements; with the exception of one drive all were within the designated range. It cannot be clearly stated that the disqualified RDE tests (drives No. 1-4, which have some disqualified parameters) are characterized by lower carbon dioxide distance emission (however, it was a value of only a few percent). Only the value obtained during drive No. 2 deviated from the average value of carbon dioxide distance emission (was smaller) by about $12.5 \%$.

- The relative error value for carbon monoxide distance emission between individual drives does not exceed 15\% (Fig. 19b); all drives were within this range (also the non-RDE compliant). In this case the highest values of relative error (extreme values, of $14.5 \%$ and $-15 \%$ ) were obtained for the accepted RDE test drives. The relative error of carbon monoxide distance emission for the disqualified test drives was lower than that of the accepted tests, i.e. the carbon monoxide distance emission measured during non-RDE compliant tests were mostly close to 
each other - as opposed to the values obtained in the tests that were in line with the RDE test procedure requirements.

a)

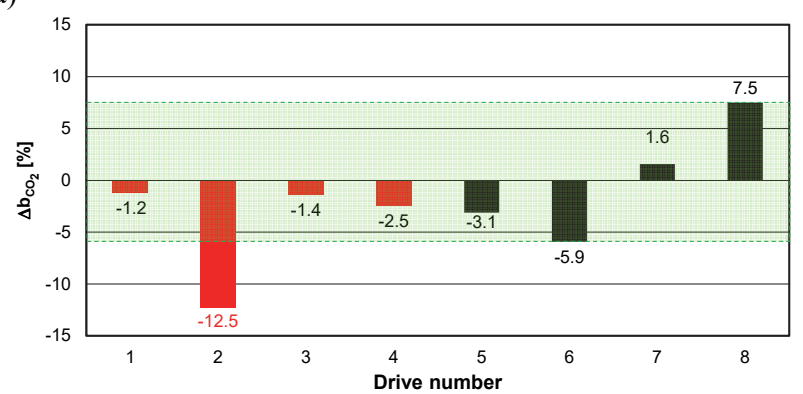

b)

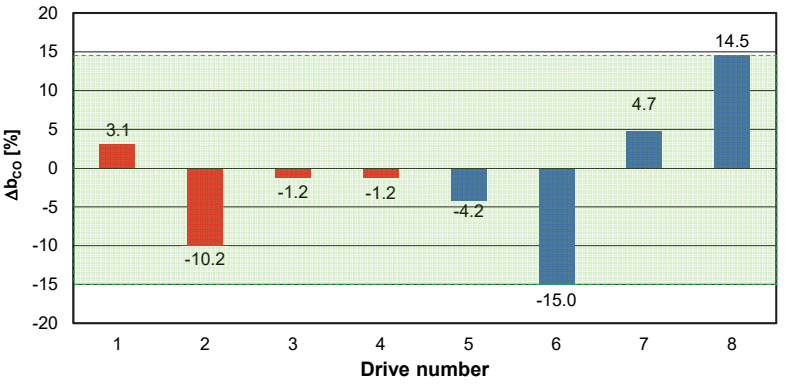

c)

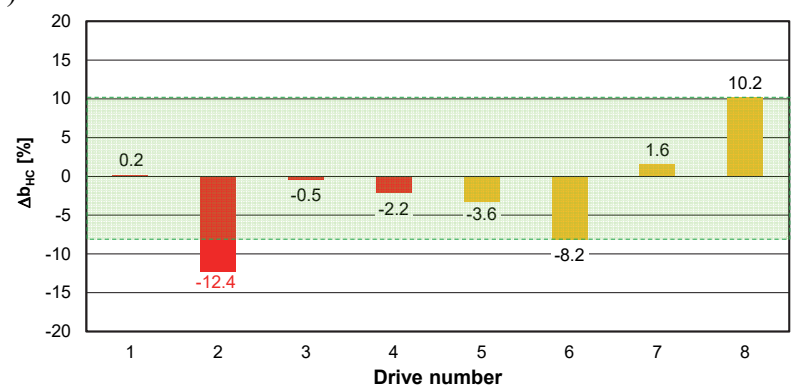

d)

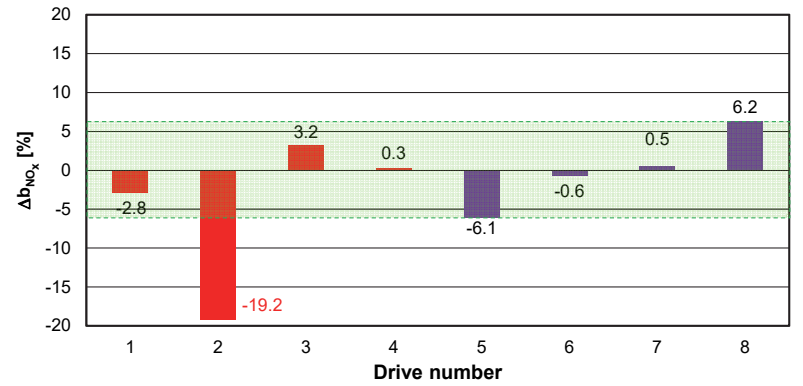

e)

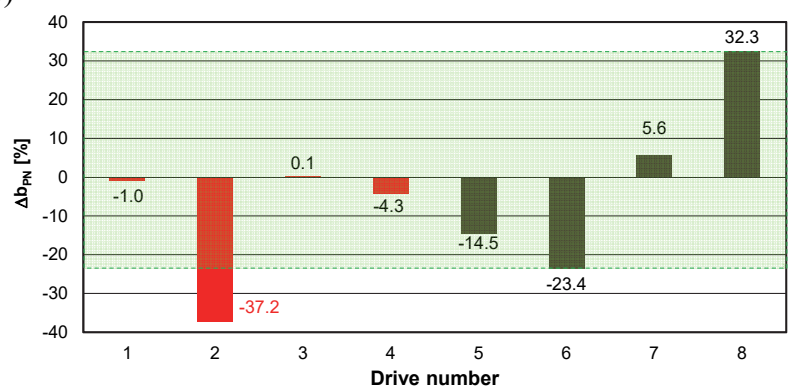

Fig. 19. Relative error for distance emission of: a) carbon dioxide, b) carbon monoxide, c) hydrocarbons, d) nitrogen oxides, e) particle number for all drives; unqualifying drives are marked with red, while the range of parameters changes from the valid test drives (No. 5-8) is marked in green.
- Hydrocarbons distance emission relative error values had a similar character as the values obtained for carbon monoxide (Fig. 19c); all drives - except for drive No. 2 again - were in the relative error range of $\pm 10 \%$, regardless of whether they were valid drives or not.

- The relative error value of the nitrogen oxide distance emission did not exceed $6 \%$ between individual drives (Fig. 19d); all drives were within this range - except for drive No. 2 (not meeting the requirements of the RDE test procedure), whose result was about $20 \%$ less than the average value of the average drive. At the same time, there is no clear trend in relative error values for the disqualified drives.

- The nature of the relative error of the particle number confirms the previous results; the relative error between each acceptable drive is the greatest among all measured emission and exceeds more than $30 \%$ (Fig. 19e); all drives were within that range - except for drive No. 2.

\section{Summary}

As of 1.09.2017, new testing procedures for determining the specific distance emission of pollutants for motor vehicles will be put in place. The European Commission has been working on them for several years, and the work is still ongoing, so the changes will be implemented in two steps. In the first phase (by 2020), the RDE tests will be used exclusively for monitoring and in the second phase (after 2020) they will be required as a part of the type approval tests. According to the new research procedure (RDE), determining pollutant exhaust emission will take place in real driving conditions. Thanks to this solution, the discrepancy between the results obtained in laboratory tests and the results obtained in road tests will be reduced. The new pollutant testing procedure has not yet been completely regulated (unlike trucks for which such conditions already exist), but there are proposals currently being examined by major research centers in Europe. These proposals differ based on the method of determining the emission values (moving average windows and power binning methods) and the test methodology including, for example, the measurement of hydrocarbon distance emission.

The article compares distance emission test data using the latest legislative proposals for passenger cars. The tests were carried out in accordance with the RDE guidelines for which a minimum test duration of 90 minutes - 120 minutes is required. The results obtained were analyzed in terms of their compliance with the requirements of the RDE procedure. Despite the similar research route, both the results of the velocity profile as well as the average velocity values in each part of the test were not the same. The driving parameters defined by acceleration, constant velocity, braking and stopping were similar. In road tests, it was shown that using a similar route led to obtaining different results in each drive, although the values were fairly close. With regard 
to the accuracy of the measurements in actual operation, it should be noted that the final result depends on the operating conditions of the vehicle. However, these conditions (such as traffic and congestion, driver's predisposition and driving style, as well as random events occurring during the drive) are unpredictable. Two-dimensional characteristics of the vehicle operating time, compiled in the vehicle velocity-acceleration coordinates, were also used in the analysis. This made it possible to compare dynamic properties, operating time shares and, consequently, to check the validity of carried out test drives.

The analysis of the individual requirements listed in Regulations 427/2016 [11] and 646/2016 [12] confirmed the validity of the RDE test procedure for four of the eight performed test drives. The invalid drives were characterized, among others, by: too short travel distance, too little operating time share of particular parts of the test, too long time spent stationary in the urban part and too little driving dynamics in the non-urban part. The analysis of the test results does not allow for unambiguous determination of the exhaust emission results inaccuracies with the assumed number of errors committed during road tests. It should be noted, however, that the highest values of distance pollutant emission were recorded for drives where a small part of the urban portion of the test was involved and a larger share of the motorway portion. This demonstrates the significant impact of the high engine load with the greatest pollutant emission intensity parts of the RDE test on the distance pollutant emission results (efficiency of the exhaust aftertreatment system is not at its peak).

The result of the study is the distance pollutant emission results value range for RDE tests carried out in accordance with the European Union procedures with the following required test parameters (for vehicles equipped with gasoline engines with direct injection systems compliant with the Euro $6 \mathrm{~b}$ norms):

- for carbon dioxide distance emission - the emission value range was $\pm 8 \%$,

- for carbon monoxide distance emission - the emission value range was $\pm 15 \%$,

- for hydrocarbons distance emission - the emission value range was $\pm 10 \%$,

- for nitrogen oxides distance emission - the emission value range was $\pm 6 \%$,

- for particle number - the value range was $\pm 32 \%$.

The article does not, however, conclusively answer the issue of what has the greater impact on the exhaust gas pollutant emission: the share of the RDE test portion or the vehicle driving dynamics (defined by the relative positive acceleration or the product of velocity and acceleration). Determining these relations will be the subject of subsequent research using passenger cars powered using different fuels as well as hybrid vehicles.

The research was funded by project co-financed by the European Regional Development Fund in the Regional Program - Lubuskie 2020 (contract No. RPLB.01.01.00-080055/16-00).

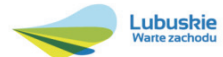

Unia Europejska Europejski Fundusz
Rozwoju Regionalnego

\section{References}

1. P. Lijewski, J. Merkisz, P. Fuc, A. Ziolkowski, L. Rymaniak, W. Kusiak, European Journal of Forest Research 136, 153-160 (2017), DOI: 10.1007/s10342-016-1015-2

2. J. Merkisz, W. Gis, WIT Transactions on the Built Environment 101, 335-344 (2008), DOI: 10.2495/UT080331

3. A. Suchecki, J. Nowakowski, T. Knefel, Transport Means - Proceedings of the International Conference, 194-197 (2014)

4. K. Prainowski, J. Mamala, IOP Conference SeriesMaterials Science and Engineering 148, UNSP 012022 (2016)

5. A. Bieniek, J. Jantos, J. Mamala, Transport 22, 247251 (2007)

6. P. Bielaczyc, J. Woodburn, D. Klimkiewicz, P. Pajdowski, A. Szczotka, Fuel Processing Technology 107, 50-63 (2013), DOI: 10.1016/j.fuproc.2012.07.030

7. N. Ligterink, G. Kadijk, P. Van Mensch, S. Hausberger, M. Rexeis, TNO Report (2013)

8. W. Stütz, International AVL Conference „Engine \& Environment" (2014)

9. T. Vlachos, P. Bonnel, A. Perujo, M. Weiss, et al. SAE Int. J. Commer. Veh. 7, 199-215 (2014)

10. I. Khalek, T. Bougher, J. Jetter, SAE International Journal of Fuels and Lubricants 3, 623-637 (2010)

11. P. Fuc, L. Rymaniak, A. Ziolkowski, WIT Transactions on Ecology and the Environment 174, 207-218 (2013), DOI: 10.2495/AIR130181

12. Commission Regulation (EC) $715 / 2007$ of the European Parliament and of the Council of 20 June 2007 on type approval of motor vehicles with respect to emissions from light passenger and commercial vehicles (Euro 5 and Euro 6) and on access to vehicle repair and maintenance information, European Commission (EC), Official J. European Union, L 171 (2007)

13. Commission Regulation (EU) 2016/427 of 10 March 2016 amending Regulation (EC) No $692 / 2008$ as regards emissions from light passenger and commercial vehicles (Euro 6), Verifying Real Driving Emissions, Official J. European Union, L 82 (2016)

14. Commission Regulation (EU) $2016 / 646$ of 20 April 2016 amending Regulation (EC) No 692/2008 as regards emissions from light passenger and commercial vehicles (Euro 6), Verifying Real Driving Emissions, Official J. European Union, L 109 (2016)

15. Commission Regulation (EC) 692/2008 of 18 July 2008 implementing and amending Regulation (EC) No 715/2007 of the European Parliament and of the Council on type-approval of motor vehicles with respect to emissions from light passenger and commercial vehicles (Euro 5 and Euro 6) and on 
access to vehicle repair and maintenance information, European Commission (EC), Official J. European Union, L 199 (2008)

16. V. Franco, M. Kousoulidou, M. Muntean, L. Ntziachristos, S. Hausberger, P. Dilara, Atmospheric Environment 70, 84-97 (2013) DOI: 10.1016/j.atmosenv.2013.01.006

17. T. Henrichs, AECC Technical Seminar on RealDriving Emissions of Particles (RDE PN), Diamant Conference Centre (2016)

18. J. Merkisz, S. Tarkowski, Eksploatacja i Niezawodnosc - Maintenance and Reliability 2, 5058 (2011)

19. M. Sobieszczanski, K. Brzozowski, J. Nowakowski, M. Tekielak, Eksploatacja i Niezawodnosc Maintenance and Reliability 3, 53-61 (2008)

20. J. Andersson, AECC Technical Seminar on RealDriving Emissions of Particles (RDE PN), Diamant Conference Centre (2016)

21. http://www.diag-tools.com/texa-obd-log-mobilnyczytnik-normy-eobd-p-478.html (11.3.2017)

22. F. Ortenzi, M.A. Costagliola, SAE Technical Paper 2010-01-1289 (2010)

23. Semtech-DS On-board vehicle emissions analyzer (2010)

24. Particle instruments: AVL Particle Counter (2010) 